\title{
Nondestructive volume estimates of 11-year-old jack pine and black spruce using the power function volume model
}

\author{
by R.R. Forslund ${ }^{1}$ and J.M. Paterson ${ }^{2}$
}

Two methods for estimating the total outside-bark stem volume of all trees in young plantations of jack pine (Pinus banksiana Lamb.) and black spruce (Picea mariana [Mill.] B.S.P.) were compared. The first method was time-intensive, and required destructive sampling to obtain volume estimates using many paired diameter/height measurements. The second method was nondestructive and required only two field measurements: an outsidebark diameter at either a fixed height (such as breast height) or at a relative height, and the total stem height. The results indicated that total plantation volume estimates to within $\pm 5 \%$ can be obtained using the power function model and two stem measurements: a diameter at a relative height of $30 \%$ from the base of the stem and total stem height. The power function model offers a good alternative for accurately assessing plantation volume.

Key words: black spruce, jack pine, power function volume model, paracone, upper diameters, profile shape, stem volume
Deux méthodes d'estimation du volume total avec écorce d'une tige pour tous les arbres retrouvés dans de jeunes plantations de pin gris (Pinus banksiana Lamb.) et d'épinette noire (Picea mariana [Mill.] B.S.P.) ont été coparées. La première méthode nécessitait beaucoup de temps ainsi que la destruction des échantillons afin d'obtenir les estimés volumétriques réalisés au moyen de plusieurs mesures jumelées du diamètre et de la hauteur. La deuxième méthode était non destructive et nécessitait seulement deux mesures sur le terrain: un diamètre avec écorce mesuré soit à une hauteur fixe (à hauteur de poitrine par ex.) ou à une hauteur relative, en plus de la hauteur totale de la tige. Les résultats ont démontré que des estimés à $\pm 5 \%$ du volume total d'une plantation peuvent être obtenus au moyen du modèle de fonction exponentielle et de deux mesures des tiges: la diamètre à une hauteur relative correspondant à $30 \%$ de la hauteur totale mesurée à partir de la souche et la hauteur totale de la tige. Le modèle de fonction exponentielle représente une alternative intéressante d'estimation précise du volume d'une plantation.

Mots clés: épinette noire, pin gris, modèle volumétrique de fonction exponentielle, paracone, diamètres supérieurs, forme du profil, volume d'une tige

\section{Introduction}

Stem volume equations can be developed either by relating volume estimates directly to stem measurements or by developing a stem profile equation and then integrating it to obtain a volume equation. The second approach has the advantage that other characteristics of the stem, such as surface area, centre of gravity and centre of mass, can be obtained from the model. Due to these capabilities, the second approach was selected as a starting point. The most logical profile model would be a sigmoidal function; but the integration of such models to obtain other stem features often becomes overwhelmingly complicated.

Due to its simplicity, the power function: $Y=X^{\mathrm{A}}$, was probably the first model ever to be used as a tree stem profile model, where the value of the power $(A)$ determines the shape of the function. Forslund (1982) and others renewed the effort to use the power function to approximate the stem profile of individual trees. The initial motivation for using the power function was to supply a simple alternative to the more complex sigmoidal stem profile models, and to provide a nondestructive method for obtaining good volume estimates. When $A=1$ in the power function model, the profile shape is a cone; when $A$ $=2$ the shape is a paraboloid, and when $A=1.5$, a paracone results. The term "paracone" was introduced by Forslund (1982), as a shape midway between a paraboloid and a cone, and was found

\footnotetext{
${ }^{1}$ Ontario Ministry of Natural Resources, Centre for Northern Forest Ecosystem Research, Lakehead University, 955 Oliver Rd, Thunder Bay, Ontario, Canada P7B 5E1.

${ }^{2}$ Ontario Ministry of Natural Resources, Ontario Forest Research Institute, 1235 Queen St. E., Sault Ste. Marie, Ontario, Canada P6A 5N5.
}

to approximate the average shape of a sample of smaller trembling aspen (Populus tremuloides Michx.). Since 1982, the paracone volume model (eq. 3) has been tested on many other species over a wide range of ages, sizes and conditions, including a larger sample of aspen (Forslund and Weingartner 1989), white birch (Betula papyrifera Marsh.), balsam fir (Abies balsamea [L.] Mill.), black spruce (Picea mariana [Mill.] B.S.P.), white spruce (Picea glauca [Moench] Voss) and aspen (MacDonald and Forslund 1986), radiata pine (Pinus radiata D. Don.) and 23 species of American and Australian hardwoods (Wiant et al. 1991). Individual stem profile shapes were found to vary between a cone and a paraboloid; but, since the paracone is midway between these two extremes of stem profile shape, it is a logical choice if the average stem shape of a sample is unknown. For all species examined, the results indicated that the paracone volume model using the diameter at $30 \%$ of the total height from the ground and total stem height will predict total volume of all trees in the sample consistently to within $\pm 5 \%$ of the value obtained by destructive sampling, and will estimate individual stem volumes to within $\pm 16 \%$ ( $95 \%$ confidence level) and more often to within $\pm 10 \%$.

There are two methods of obtaining volume with the power function model depending on which diameter measurement is taken: (1) a diameter $\left(\mathrm{D}_{0.3}\right)$ at a relative height located at $30 \%$ of the total height measured from the base of the stem, or (2) a diameter (DBH) at a fixed height of 1.30 metres from the base of the stem. Method (1) provides the most reliable volume estimates since the $30 \%$ position is a location of shape stability (Forslund 1991a) for volume estimation. This stability position is simply a result of the geometry of the volume equations, and not that the centre of gravity occurs near this posi- 
tion, as previously thought by Forslund (1982). Method (1), however, has the disadvantage that a diameter at a relative height is more difficult to obtain since its position must be calculated prior to measurement in the field, and the $30 \%$ position is often beyond reach.

As long as $\mathrm{D}_{0.3}$ is measured, the model will produce good results using the paracone model. However, if a diameter at a fixed height is measured, it is usually located either above or below the position of shape stability. In this case, an estimate of either the average stem profile shape (power A), or more ideally, an estimate of how the shape of each stem profile changes under a given set of factors is required. Several factors affecting profile shape are already known. The factors that affect stem profile shape were studied by MacDonald and Forslund (1986), who examined five different species and found that each species had a different average stem profile shape using the power function. More recently, Morris and Forslund (1992) have examined environmental factors affecting stem profile shape. If the average profile shape of trees in the sample is known, and the variation in individual stem profile shapes is minimal, then this specific power (A) can be used to provide good volume estimates using DBH. If the average stem profile shape is not known, the paracone can be used to approximate the average stem profile.

Why do we need the power function model and why not use existing regression models? These traditional volume models require destructive sampling in order to calibrate a regression equation that involves several variables, usually including DBH. Although the regression approach provides accurate volume predictions for specific sites, the models cannot generally be extended to different sites without further destructive sampling and recalibration of the equation. In addition, the regression models are usually not profile models, but rather predict volume directly from the measurements which have the disadvantage previously mentioned. In an unpublished paper (Forslund 1991b), 16 regression equations were compared with the power function model. The power function model provided volume predictions comparable to these regression equations and was often significantly better. The power function model has the additional advantage that it allows the development of other formulae for various features of the stem (Forslund 1991a), and can be developed into an even more accurate tool as the factors affecting stem profile shape are identified.

The power function model offered an alternative to the traditional regression techniques and provided a logical foundation on which to improve volume prediction. The objective of this paper was to compare volume estimates obtained from the power function model with those obtained from traditional, destructive stem analysis methods in 11-year-old jack pine (Pinus banksiana Lamb.) and black spruce plantations. The jack pine sample was of primary interest since the power function model had not been tested previously on this species.

\section{Methods}

By integrating the power function model of the stem profile, the following general power function volume model (Forslund 1982) results :

$$
\mathrm{V}=\frac{A}{(A+2)}(1-Y)^{(-2 / \mathrm{A})} \frac{\pi D_{\mathrm{Y}}^{2} H C}{4}
$$

where $\mathrm{V}$ is the total stem volume (outside bark), $\mathrm{D}_{\mathrm{Y}}$ is the outside bark diameter at a relative height $Y=h / H$ on the stem, $h$ is the height to the measurement position from the ground, $\mathrm{H}$ is the total stem height, $A$ is the power that determines the shape of the stem profile, and $\mathrm{C}$ is the units conversion factor. Descriptions of the development of this model can be found in Forslund (1982, 1991a).

The general volume model (eq. 1) was subdivided into six specific cases for use in this report. Using eq. 1 with $A=1,1.5$ and 2 resulted in the cone, paracone and paraboloid respectively. For each of these three cases, the diameter $\left(\mathrm{D}_{0.3}\right)$ at the $30 \%$ height position and the diameter $(\mathrm{DBH})$ at breast height were also tested. This resulted in the following six specific variations of the power function model:

For $\mathrm{D}_{0.3}$, the following 3 models result :

$$
\begin{aligned}
& \text { Cone : } \begin{aligned}
V_{0.3} & =1 / 3(1-0.3)^{(-2)} \pi\left(\mathrm{D}_{0.3}{ }^{2} / 4\right) \mathrm{HC} \\
& =0.534284 \mathrm{D}_{0.3}{ }^{2} \mathrm{HC}
\end{aligned} \\
& \text { Paracone : } V_{0.3}=3 / 7(1-0.3)^{(-4 / 3)} \pi\left(\mathrm{D}_{0.3}{ }^{2} / 4\right) \mathrm{H} \mathrm{C} \\
& =0.541563 \mathrm{D}_{0.3}^{2} \mathrm{HC} \\
& \text { Paraboloid : } \begin{aligned}
V_{0.3} & =1 / 2(1-0.3)^{(-1)} \pi\left(\mathrm{D}_{0.3}{ }^{2} / 4\right) \mathrm{H} \mathrm{C} \\
& =0.560999 \mathrm{D}_{0.3}{ }^{2} \mathrm{H} \mathrm{C}
\end{aligned}
\end{aligned}
$$

Eqs. 2-4 are simply a constant times the volume of a cylin$\operatorname{der}\left(\pi\left(\mathrm{D}_{0.3}{ }^{2} / 4\right) \mathrm{H}\right)$. Therefore, the various constants (except the units conversion factor, $\mathrm{C}$ ) have been combined into one constant as shown in order to provide a simple, useable model. For the present data sample, the units conversion factor $(C)$ is $(0.10)$, since the diameters are in centimetres, heights in metres and volumes in cubic decimetres. Volumes were calculated in cubic decimetres rather than the standard cubic metres in order to simplify the presentation of the small mean stem volume values (Table 1). Due to the measurement of a diameter near the position of shape stability, eqs. 2-4 should provide good stem volume estimates regardless of species, stem form, age, and other factors, provided the stems are free from deformities such as forks and other abnormal branching.

For $\mathrm{DBH}$, the following 3 models result :

$$
\begin{array}{r}
\text { Cone: } V_{\mathrm{DBH}}=1 / 3(1-1.3 / H)^{(-2)} \pi\left(\mathrm{DBH}^{2} / 4\right) \mathrm{H} \mathrm{C} \\
\text { Paracone: } \mathrm{V}_{\mathrm{DBH}}=3 / 7(1-1.3 / H)^{(-4 / 3)} \pi\left(\mathrm{DBH}^{2} / 4\right) \mathrm{HC} \\
\text { Paraboloid: } \mathrm{V}_{\mathrm{DBH}}=1 / 2(1-1.3 / H)^{(-1)} \pi\left(\mathrm{DBH}^{2} / 4\right) \mathrm{HC}
\end{array}
$$

The breast height cases (eqs. 5-7) are slightly more complicated than the corresponding relative height cases (eqs. 2-4), since they require the calculation of the tree's form factor:

$$
\frac{A}{(A+2)}\left[1-\frac{1.3}{H}\right]^{(-2 / \mathrm{A})}
$$

This factor results when the profile equation is integrated and is complicated by the use of a diameter (DBH) at a fixed rather than a relative height. The form factor properly adjusts the volume using a relative height of $(1.3 / \mathrm{H})$ rather than a fixed height of 1.3 metres. Note that heights must be in metres in eqs. $5-7$, so that $(1.3 / \mathrm{H})$ becomes the proper relative height.

During the fall of 1989 , subsamples of jack pine and black 
Table 1. Mean ${ }^{1}$ stem volumes using Smalian's formula and those calculated using cone, paracone and paraboloid models with diameters at $30 \%$ of the total height and at breast height for jack pine and black spruce

\begin{tabular}{|c|c|c|c|c|c|c|c|}
\hline \multirow[b]{3}{*}{ Treatment } & \multicolumn{7}{|c|}{ Volumes $\left(\mathbf{d m}^{3}\right)$} \\
\hline & \multirow[b]{2}{*}{ Smalian } & \multicolumn{3}{|c|}{ Model (using $\mathrm{D}_{0.3}$ and $\mathrm{H}$ ) } & \multicolumn{3}{|c|}{ Model (using DBH and H) } \\
\hline & & Cone & Paracone & Paraboloid & Cone & Paracone & Paraboloid \\
\hline \multicolumn{8}{|l|}{ Jack pine } \\
\hline 3 & 10.19 & $10.47 *$ & 10.61 & 10.99 & $10.49 *$ & 11.08 & 11.71 \\
\hline 4 & 6.99 & $6.99 *$ & 7.09 & 7.34 & $7.08 *$ & 7.32 & 7.66 \\
\hline 5 & 7.80 & $7.90^{*}$ & 8.01 & 8.29 & $7.78 *$ & 8.06 & 8.45 \\
\hline 7 & 9.15 & $9.26 *$ & 9.38 & 9.72 & $9.03 *$ & 9.51 & 10.05 \\
\hline 8 & 6.10 & $6.31 *$ & 6.40 & 6.63 & $6.19 *$ & 6.31 & 6.56 \\
\hline 9 & 6.51 & $6.69 *$ & 6.78 & 7.03 & $6.65^{*}$ & 6.84 & 7.15 \\
\hline 11 & 8.21 & $8.32 *$ & 8.43 & 8.73 & $8.20 *$ & 8.60 & 9.06 \\
\hline 12 & 5.31 & $5.40 *$ & 5.48 & 5.67 & $5.45^{*}$ & 5.54 & 5.75 \\
\hline 13 & 5.42 & $5.45^{*}$ & 5.53 & 5.73 & $5.49 *$ & 5.53 & 5.72 \\
\hline 14 & 4.66 & $4.68 *$ & 4.74 & 4.91 & $4.84 *$ & 4.85 & 5.00 \\
\hline 15 & 5.32 & $5.39 *$ & 5.46 & 5.66 & $5.44 *$ & 5.53 & 5.73 \\
\hline 17 & 4.21 & $4.46^{*}$ & 4.52 & 4.68 & $4.48^{*}$ & 4.67 & 4.59 \\
\hline 18 & 4.75 & $4.85^{*}$ & 4.92 & 5.09 & $4.85^{*}$ & 4.89 & 5.06 \\
\hline All & 6.50 & $6.63 *$ & 6.72 & 6.96 & $6.61^{*}$ & 6.81 & 7.11 \\
\hline \multicolumn{8}{|l|}{ Black spruce } \\
\hline 1 & 1.28 & 1.19 & 1.21 & $1.25^{*}$ & $1.32 *$ & 1.07 & 1.01 \\
\hline 2 & 0.58 & 0.55 & 0.55 & $0.57 *$ & 0.73 & $0.48^{*}$ & 0.42 \\
\hline 6 & 0.87 & 0.81 & 0.82 & $0.85^{*}$ & $1.01 *$ & 0.68 & 0.60 \\
\hline 10 & 0.68 & 0.64 & 0.64 & $0.67 *$ & $0.73 *$ & 0.52 & 0.46 \\
\hline 16 & 0.47 & 0.45 & 0.45 & $0.47 *$ & 0.80 & $0.42 *$ & 0.35 \\
\hline All & 0.77 & 0.73 & 0.74 & $0.76^{*}$ & 0.93 & $0.65^{*}$ & 0.58 \\
\hline
\end{tabular}

${ }^{1}$ The means are based on 25 stems per treatment resulting in a total of 325 jack pine and 125 black spruce (116 stems for volume estimates of black spruce using DBH since 9 stems were too short to measure DBH). The values followed by an asterisk are the closest values to those calculated using Smalian's model.

spruce trees were removed from an experimental planting north of Wawa, Ontario $\left(48.36^{\circ} \mathrm{N}, 83.55^{\circ} \mathrm{W}\right)$ to calculate stem volume. The trees were part of a larger experiment that was established in the spring of 1979 to study the field performance of various jack pine and black spruce stock types planted over several dates on both a dry and a fresh site. Information presented previously (Glerum and Paterson 1989) showed how volume growth can be influenced by microsite. In the present paper, only the trees on the dry site were used.

In the experimental design on the dry site, 13 jack pine and five black spruce treatments were compared for a total of 18 treatments (Appendix 1). Each treatment consisted of five replications of 35 trees each (treatments 1-5 and 16) or 50 trees each (treatments 6-15, 17 and 18), planted in a randomized block design.

From each replication, five trees were selected at random for stem analysis, which resulted in 25 trees per treatment for a total of 325 jack pine and 125 black spruce. The trees were felled, total tree height was measured, and discs were removed from each tree at 10 (height at which tree was cut), 30, 60, 90, 120, 130 (breast height) and $150 \mathrm{~cm}$, and at 50 -cm intervals from here to the top of the tree. The jack pine ranged in total height from 2.03 to $6.29 \mathrm{~m}$ and the black spruce heights ranged from 1.02 to $3.48 \mathrm{~m}$. If a branch whorl or stem deformity occurred at the predetermined heights, then the disc height was adjusted up or down the stem and the new height recorded prior to removing the disc. By using this intensive sampling procedure, an accurate estimate of stem volume could be achieved using "TRIM" (Tree Ring Increment Measuring System), as described by Fayle and MacIver (1986).

During the fall and winter of $1989 / 90$, the discs were measured using the TRIM system. The TRIM measurements pro- vided an outside-bark diameter for each section height, which could be used to estimate outside-bark volume. Diameter increased at upper stem positions on a few stems (especially the jack pine). The wood discs were re-examined and it was found that the diameter increases were caused either by a disc being taken near a branch whorl or by the disc being cut at an angle, thus creating larger diameters. These cases were corrected by using an average of the disc diameters above and below the bulge position. Since the diameter at the $30 \%$ of height $\left(D_{0.3}\right)$ position was not measured, it was interpolated linearly from the diameters obtained from the TRIM analysis.

Using the TRIM data, the outside bark volume of each stem was determined using Smalian's formula. Six volume estimates were then calculated using eqs. 2-7 and the diameter and height data. (Nine of the black spruce stems were less than 1.3 metres in height, and were therefore omitted in the volume calculations using $\mathrm{DBH}$.) The sample was also stratified by treatment to examine how the power function volume model performed for a variety of stock types. The volumes were summed for each treatment and the mean volume of all stems within a treatment was calculated to reflect the total volume of all stems in the plantation (Table 1). Percentage differences in mean volume (Table 2 ) were calculated using :

$$
(Y-X) / X^{*} 100 \%
$$

where $X$ is the true value (Smalian's volume in this case) and $Y$ is the estimated value (volume estimates from eqs. 2-7)

As a test of the accuracy of individual volume estimates, a modification of Freese's (1960) chi-square test of accuracy (Rennie and Wiant 1978) was also performed. The formula for this value $( \pm \mathrm{P})$ (Table 3) follows : 
Table 2. Percentage differences ${ }^{1}$ in mean stem volume estimates (relative to Smalian's model) using cone, paracone and paraboloid models with diameters at $30 \%$ of the total height and at breast height for jack pine and black spruce

\begin{tabular}{|c|c|c|c|c|c|c|}
\hline \multirow[b]{3}{*}{ Treatment } & \multicolumn{6}{|c|}{ Mean volume differences (\%) } \\
\hline & \multicolumn{3}{|c|}{ Model (using $\mathrm{D}_{0.3}$ and $\mathrm{H}$ ) } & \multicolumn{3}{|c|}{ Model (using DBH and H) } \\
\hline & Cone & Paracone & Paraboloid & Cone & Paracone & Paraboloid \\
\hline \multicolumn{7}{|l|}{ Jack pine } \\
\hline 3 & $2.7^{*}$ & 4.1 & 7.8 & $3.0 *$ & 8.7 & 14.9 \\
\hline 4 & $0.1 *$ & 1.4 & 5.1 & $1.3 *$ & 4.7 & 9.6 \\
\hline 5 & $1.3 *$ & 2.7 & 6.3 & $-0.3 *$ & 3.4 & 8.3 \\
\hline 7 & $1.1^{*}$ & 2.5 & 6.2 & $-1.4 *$ & 3.9 & 9.8 \\
\hline 8 & $3.6 *$ & 5.0 & 8.7 & $1.5^{*}$ & 3.5 & 7.6 \\
\hline 9 & $2.8^{*}$ & 4.2 & 7.9 & $2.1^{*}$ & 5.1 & 9.7 \\
\hline 11 & $2.4^{*}$ & 3.8 & 7.5 & $1.0^{*}$ & 5.9 & 11.6 \\
\hline 12 & $1.9 *$ & 3.3 & 7.0 & $2.7 *$ & 4.4 & 8.4 \\
\hline 13 & $0.6^{*}$ & 1.9 & 5.6 & $1.1^{*}$ & 2.0 & 5.4 \\
\hline 14 & $0.4 *$ & 1.8 & 5.4 & $4.0^{*}$ & 4.1 & 7.4 \\
\hline 15 & $1.3 *$ & 2.7 & 6.4 & $2.4^{*}$ & 3.9 & 7.7 \\
\hline 17 & $5.8^{*}$ & 7.2 & 11.0 & $6.2 *$ & $6.0 *$ & 9.0 \\
\hline 18 & $2.1^{*}$ & 3.5 & 7.2 & $2.0^{*}$ & 2.9 & 6.5 \\
\hline All & $1.9^{*}$ & 3.3 & 7.0 & $1.7^{*}$ & 4.7 & 9.4 \\
\hline \multicolumn{7}{|l|}{ Black spruce } \\
\hline 1 & -6.5 & -5.3 & $-1.9^{*}$ & $3.7 *$ & -15.9 & -20.9 \\
\hline 2 & -5.2 & -3.9 & $-0.5^{*}$ & $10.8^{*}$ & -27.5 & -37.0 \\
\hline 6 & -6.4 & -5.1 & $-1.7 *$ & $16.8^{*}$ & -21.7 & -30.8 \\
\hline 10 & -6.5 & -5.2 & $-1.8^{*}$ & $4.8^{*}$ & -25.2 & -34.3 \\
\hline 16 & -6.1 & -4.8 & $-1.4^{*}$ & 47.8 & $-22.7^{*}$ & -35.4 \\
\hline All & -6.2 & -5.0 & $-1.5^{*}$ & $13.2^{*}$ & -21.3 & -29.5 \\
\hline
\end{tabular}

${ }^{1}$ The values followed by an asterisk are closest to those produced by Smalian's model.

Table 3. Percentage variation $( \pm \mathrm{P})^{1}$ in individual stem volume estimates (relative to Smalian's model) using cone, paracone and paraboloid models with diameters at $30 \%$ of the total height and at breast height for jack pine and black spruce

\begin{tabular}{|c|c|c|c|c|c|c|}
\hline \multirow[b]{3}{*}{ Treatment } & \multicolumn{6}{|c|}{ Individual stem volume variation $( \pm \mathrm{P} \%)$} \\
\hline & \multicolumn{3}{|c|}{ Model (using $\mathrm{D}_{0,3}$ and $\mathrm{H}$ ) } & \multicolumn{3}{|c|}{ Model (using DBH and $\mathrm{H}$ ) } \\
\hline & Cone & Paracone & Paraboloid & Cone & Paracone & Paraboloid \\
\hline \multicolumn{7}{|l|}{ Jack pine } \\
\hline 3 & $10.0^{*}$ & 11.4 & 16.1 & $10.9^{*}$ & 15.1 & 23.6 \\
\hline 4 & $12.0 *$ & 12.7 & 15.9 & 12.9 & $12.8^{*}$ & 18.2 \\
\hline 5 & $12.1 *$ & 13.0 & 16.8 & 12.3 & $12.4^{*}$ & 17.4 \\
\hline 7 & $8.3^{*}$ & 9.0 & 12.7 & $9.7 *$ & 11.7 & 18.4 \\
\hline 8 & $10.2^{*}$ & 11.5 & 16.1 & $10.0^{*}$ & $10.0^{*}$ & 15.1 \\
\hline 9 & $8.9 *$ & 10.2 & 14.9 & $8.5^{*}$ & 10.3 & 16.4 \\
\hline 11 & $9.6 *$ & 10.8 & 15.1 & $8.5^{*}$ & 12.4 & 20.0 \\
\hline 12 & $9.8^{*}$ & 10.5 & 14.2 & $14.6^{*}$ & 17.8 & 21.9 \\
\hline 13 & $11.8^{*}$ & 12.3 & 15.3 & 12.4 & $11.6^{*}$ & 14.5 \\
\hline 14 & $10.3 *$ & 10.7 & 13.4 & 36.0 & 15.3 & $14.7 *$ \\
\hline 15 & $10.6 *$ & 11.4 & 15.2 & 12.7 & $11.9 *$ & 15.7 \\
\hline 17 & $13.7 *$ & 15.1 & 19.7 & 14.1 & $11.4 *$ & 15.4 \\
\hline 18 & $10.5^{*}$ & 11.4 & 15.2 & $11.7 *$ & 13.6 & 17.4 \\
\hline All & $12.3^{*}$ & 13.4 & 17.9 & 17.4 & $14.9^{*}$ & 20.5 \\
\hline \multicolumn{7}{|l|}{ Black spruce } \\
\hline 1 & 17.9 & 16.5 & $13.5^{*}$ & 54.3 & $54.1^{*}$ & 68.8 \\
\hline 2 & 13.2 & 12.5 & $12.2 *$ & 213.0 & $62.3^{*}$ & 79.2 \\
\hline 6 & 15.4 & 14.3 & $12.7^{*}$ & 129.8 & $56.7^{*}$ & 74.1 \\
\hline 10 & 17.3 & 16.8 & $16.7^{*}$ & 73.4 & $53.8^{*}$ & 67.4 \\
\hline 16 & 13.7 & $13.4^{*}$ & 14.4 & 356.1 & $71.3^{*}$ & 88.5 \\
\hline All & 17.4 & 16.5 & $15.5^{*}$ & 215.0 & $66.5^{*}$ & 84.3 \\
\hline
\end{tabular}

${ }^{1}$ The values were calculated using Rennie and Wiant (1978) and mean that individual stem volume error will exceed these values only one time in 20 (95\% confidence). The values followed by an asterisk are those with the smallest error relative to Smalian's model.

$$
\pm \mathrm{P}=\sqrt{ }\left(\sum(Y / X-1)^{2} / \chi^{2}\right) * 1.96 * 100 \%
$$

where $\chi^{2}$ is the chi-square value which depends on the sample size, and 1.96 is the standard normal deviate for a confidence level of $95 \%$.

\section{Results and Discussion}

The mean volume estimates from each of the six variations of the power function model are provided (Table 1). As expected, the volume estimates generally increase as the value of the power (A) increases. In other words, volume estimates 
using a cone will generally be less than those with a paracone, which in turn will be less than paraboloidal estimates. Due to the nature of the model, however, when the diameter at a fixed measurement position (breast height, in this case) is above the shape stability position, the volume estimates will decrease as the value of $\mathrm{A}$ increases. This can be seen in the three DBH models for black spruce for which breast height was generally located above the shape stability position.

The three cases using $\mathrm{D}_{0.3}$ provide better volume estimates than the corresponding three using DBH (Tables 2 and 3). Within the specific models using $\mathrm{D}_{0.3}$, the best volume estimates for the jack pine sample were obtained using a cone, whereas the model performed best for black spruce using a paraboloid. MacDonald and Forslund (1986) also found that the paraboloid model worked best for black spruce. The authors caution the reader not to conclude that jack pine are generally conical in stem profile shape. This conclusion requires a further examination of the average stem profile shape of jack pine and cannot be made solely from the volume predictions.

The percent difference in the mean volume (Table 2) is generally less than $\pm 5 \%$ for both species. The value of $\pm \mathrm{P} \%$ (Table 3) indicates that the percentage volume error for individual stems will exceed this P value only one time in 20 (a 95\% confidence level). If the appropriate power is selected, the model predicts individual stem volumes for both species to within $\pm 16 \%$ using the $30 \%$ height position.

As expected, the volume estimates using $\mathrm{DBH}$ were generally poorer than the corresponding estimates using $\mathrm{D}_{0.3}$ for both species. The relatively good results using $\mathrm{DBH}$ for jack pine were because breast height was usually located near the $30 \%$ position for this sample. This can be illustrated by noting that the average tree height was 4.43 metres, which locates the $30 \%$ position at 4.43 $* 0.3=1.33$ metres. Also notice the extremely poor estimates using DBH for black spruce. These poor estimates occurred because the black spruce sample consisted mostly of small stems which resulted in the location of $\mathrm{DBH}$ in the upper third of the stem. Volume estimates using DBH rather than the $30 \%$ position will generally be poorer (Tables 2 and 3 ) unless the profile shape is identified more precisely. In addition, on trees where height is less than $1.3 \mathrm{~m}$, which was the case for nine stems in the black spruce sample, DBH simply cannot be taken and a diameter at the $30 \%$ position is necessary to obtain a volume estimate.

Finally, the percentage error was relatively stable among all treatments. In the conical model for jack pine, for example, the percentage differences (Table 2) are all less than $6 \%$, and most are less than $3 \%$. The paraboloid model used with black spruce also produces errors of less than $2 \%$ for all treatments. This suggests that the power function model may be independent of the stock type.

\section{Conclusions and Recommendations}

The paracone model is a specific power function model with a power value of $\mathrm{A}=1.5$, which represents a stem profile midway between a paraboloid $(\mathrm{A}=2)$ and a cone $(\mathrm{A}=1)$. The model provides better volume estimates if diameters are measured at a specific relative height located at $30 \%$ of the total tree height from the stem base rather than using breast-height diameters. The simplified paracone model using the outside-bark diameter $\left(\mathrm{D}_{0.3}\right)$ and total stem height $(\mathrm{H})$ is: $\mathrm{V}=0.541563 * \mathrm{D}_{0.3}{ }^{2}$ $* \mathrm{H} * \mathrm{C}$, where $\mathrm{V}$ is the total outside-bark stem volume and $\mathrm{C}$ is the measurement units conversion factor.

The results of this analysis indicate that the mean outside bark volume, and hence the total volume of young plantations of both jack pine and black spruce plantations can be estimated nondestructively to within $\pm 5 \%$ by measuring a diameter at the $30 \%$ position plus the total stem height. In addition, individual stem estimates to within $\pm 16 \%$ of the true value ( $95 \%$ confidence) were obtained for both species. Somewhat improved volume estimates were obtained using a conical model for jack pine and a paraboloid for black spruce rather than the paracone model. The resulting percentage differences in mean volume estimates improved from $3.3 \%$ (paracone) to $1.9 \%$ (cone) for jack pine, and from $-5.0 \%$ (paracone) to $-1.5 \%$ (paraboloid) for black spruce. The corresponding individual stem volume error (95\% confidence) improved slightly from $13.4 \%$ to $12.3 \%$, for jack pine and from $16.5 \%$ to $15.5 \%$ for black spruce. Finally, the estimates appear to be independent of the stock type.

Recommendations and precautions on the use of the power function volume model:

(1) The model is best suited to smaller stems such as are found in young plantations, for which the $30 \%$ of height position can be reached without the use of a ladder. It is an ideal model to use when the total height of the stems is less than $7 \mathrm{~m}$, and also has application for trees that have not yet achieved breast height. Although it is more convenient to measure the diameter at breast height (provided the trees are tall enough), the extra effort required in the field to locate the $30 \%$ of height position before the diameter is measured can be justified by the resulting improvement in volume estimates which are comparable to those obtained with destructive sampling.

(2) Since the percentage error in individual stem volumes can exceed the yearly percentage volume increment, the model should not be used to estimate yearly volume increment for individual stems. Total volume increment for the plantation can be obtained by summing the yearly increments obtained by remeasuring yearly; however, the accuracy of these estimates has not yet been examined.

(3) If you are using a portable data collector to record $\mathrm{D}_{0.3}$ and total height, measure the height first and leave the height pole on the stem. Then have the data collector's software calculate and display the height to the $30 \%$ position after which the position can be located on the height pole, and $\mathrm{D}_{0.3}$ measured.

(4) Extra care must be taken to measure $\mathrm{D}_{0.3}$ and $\mathrm{H}$ if they will be used to replace the stem analysis method of volume determination. If a bulge or other deformity occurs at the $30 \%$ measurement position, then two diameter measurements equidistant from this position should be averaged. The idea is to obtain a diameter measurement as if the stem were a smooth geometrical solid.

(5) Trees with irregularities such as forking present a problem that has not yet been addressed. A possible solution is to measure the height to the tallest leader, and then measure the diameters of each major fork at the $30 \%$ position. Next calculate a total basal area $\left(\mathrm{BA}=\Sigma\left[\pi * \mathrm{D}_{0.3}{ }^{2} / 4\right]\right)$ for all of the diameter measurements and finally calculate the diameter of the stem that would have this basal area : $\mathrm{D}_{0.3}=\sqrt{ }[4 * \mathrm{BA} / \pi]$, and use this representative value to calculate volume using eqs. $2-4$. This procedure can be incorporated into the software for a data collector 
so that the operator is prompted for the diameters of all major branches at the $30 \%$ position, and the program then calculates and stores the appropriate "average" diameter. The accuracy of this procedure still needs validation by comparing predictions with a proven method such as immersion volume, but does provide an interim solution to address this problem.

\section{Acknowledgements}

We would like to thank Dr. Voyteck Zakrzewski, Dr. Blake MacDonald and David Weingartner of the Ontario Forest Research Institute; Geoffrey Hart of Forestry Canada; Dr. Peter Marshall of the University of British Columbia and an anonymous referee for their very constructive reviews of this paper.

\section{References}

Fayle, D.C.F. and D.C. MacIver. 1986. Growth layer analysis as a method of examining tree growth and development responses. pp. 40-48 In D.S. Solomon and T.B. Brann (eds.). Proc. of environmental influences on tree and stand increment. Univ. Maine, Maine Agric. Exp. Sta., Misc. Publ. 691.

Forslund, R.R. 1982. A geometrical tree volume model based on the location of the centre of gravity of the bole. Can. J. For. Res. 12(2): 215-221.

Forslund, R.R. 1991a. The power function as a simple stem profile examination tool. Can. J. For. Res. 21(2):193-198.
Forslund, R.R. 1991b. A stem profile generation technique used to compare volume models. Unpublished paper.

Forslund, R.R. and D.H. Weingartner. 1989. Profile comparisons and bole volume estimates based on the paracone model. In Forestry Research Marketplace: results in action. p. 105, 21-23 November, 1989. Forestry Canada, Ontario region, Sault Ste. Marie, Ont. OFRC Symp. Proceedings O-P-18. (Poster Abst.) 151 p.

Freese, F. 1960. Testing accuracy. For. Sci. 6(2): 139-145.

Glerum, C. and J.M. Paterson. 1989. Climatic influences on jack pine and black spruce during eight growing seasons since planting on a dry and fresh site in Northern Ontario. In A.N. Auclair, D.C. MacIver and R.B. Street (eds.). Proc. Forest Climate '86 - Climate applications in forest renewal and production, Orillia, Ontario.

MacDonald, G.B. and R.R. Forslund. 1986. Application of a geometrical volume equation to species with different bole forms. Can. J. For. Res. 16(2): 311-314.

Morris, D.M. and R.R. Forslund. 1992. The relative importance of competition, microsite, and climate in controlling the stem taper and profile shape in jack pine. Can. J. For. Res. 22(12): 1999-2003. Rennie, J.C. and H.V. Wiant, Jr. 1978. Modification of Freese's chisquare test of accuracy. Bureau of Land Management, Department of the Interior, Washington, DC. Resour. Invent. Notes BLM 14. pp. 1-3. Wiant, H.V. Jr., G.B. Wood and R.R. Forslund. 1991. Comparison of centroid and paracone estimates of tree volume. Can. J. For. Res. 21(5): 714-717.

\begin{tabular}{|c|c|c|c|c|}
\hline \multicolumn{5}{|c|}{ Appendix 1. Stock types, planting dates and nursery origin of jack pine and black spruce used in the 1979 Wawa planting } \\
\hline $\begin{array}{c}\text { Treatment } \\
\text { number }\end{array}$ & Stock type & Planting date & Nursery & $\begin{array}{c}\text { Number of trees } \\
\text { planted }\end{array}$ \\
\hline \multicolumn{5}{|l|}{ Jack pine } \\
\hline 3 & $2+0$ bare root & May 30 & Thessalon & 175 \\
\hline 4 & overwintered 408 Japanese paperpot & May 30 & Thessalon & 175 \\
\hline 5 & overwintered Rootrainers & May 30 & White River ${ }^{1}$ & 175 \\
\hline 7 & $2+0$ bare root & June 13 & Thessalon & 250 \\
\hline 8 & overwintered 408 Japanese paperpot & June 13 & Thessalon & 250 \\
\hline 9 & overwintered Rootrainers & June 13 & White River & 250 \\
\hline 11 & $2+0$ bare root & June 26 & Thessalon & 250 \\
\hline 12 & overwintered 408 Japanese paperpot & June 26 & Thessalon & 250 \\
\hline 13 & overwintered Rootrainers & June 26 & White River & 250 \\
\hline 14 & spring sown 408 Japanese paperpot & June 28 & Thessalon & 250 \\
\hline 15 & spring sown 408 Japanese paperpot & June 28 & Maple Research ${ }^{2}$ & 250 \\
\hline 17 & spring sown 408 Japanese paperpot & July 10 & Thessalon & 250 \\
\hline 18 & spring sown 408 Japanese paperpot & July 10 & Maple Research & 250 \\
\hline \multicolumn{5}{|l|}{ Black spruce } \\
\hline 1 & $1 \frac{1}{2}+1 \frac{1}{2}$ bare root & May 30 & Swastika & 175 \\
\hline 2 & overwintered 408 Japanese paperpot & May 30 & Thessalon & 175 \\
\hline 6 & $1 \frac{1}{2}+1 \frac{1}{2}$ bare root & June 13 & Swastika & 250 \\
\hline 10 & $1 \frac{1}{2}+1 \frac{1}{2}$ bare root & June 26 & Swastika & 250 \\
\hline 16 & overwintered 408 Japanese paperpot & June 28 & Thessalon $^{3}$ & 175 \\
\hline
\end{tabular}

${ }^{1}$ The White River nursery was located at the White River district office of the Ontario Ministry of Natural Resources and was a small-scale greenhouse nursery operation that produced stock for local use. The district office and nursery facility are no longer in operation.

${ }^{2}$ This was an attempt at growing stock in Southern Ontario and transporting it to planting sites in Northern Ontario. The stock was produced in glass greenhouses at the Ontario Ministry of Natural Resources Forest Research complex at Maple, Ontario.

${ }^{3}$ Same stock as treatment 2 , but retained at nursery to achieve greater height growth prior to shipment, then shipped as an actively growing current crop. 